\title{
Pseudoephedrine Measurement
}

National Cancer Institute

\section{Source}

National Cancer Institute. Pseudoephedrine Measurement. NCI Thesaurus. Code C74696.

The determination of the amount of pseudoephedrine present in a sample 